\title{
Crecimiento Económico y Evolución de las Finanzas Públicas en El Ecuador: Periodo 2008-2020
}

\section{Economic Growth and Evolution of Public Finances \\ in Ecuador: 2008-2020}

\author{
Luis Alberto DÁVILA-TORO'
}

1. Universidad UTE, Facultad de Ciencias Administrativas, Ecuador.

\section{Resumen}

En este artículo se aborda la evolución del crecimiento económico del Ecuador a partir del año 2008, como producto de la primera reforma tributaria impulsada por el gobierno del expresidente Rafael Correa. Con posterioridad, en menos de una década, se aplicaron 22 reformas tributarias. Por este motivo, es importante revisar el impacto definitivo que dichas reformas hacendarias han tenido en la recaudación fiscal, así como en el aumento del gasto público a nivel nacional. Como resultado de la implementación de esta política fiscal expansiva, la economía ecuatoriana experimentó un crecimiento económico que dependia de los ingresos petroleros del pais. Consecuentemente, cuando los ingresos cayeron, ocasionaron un grave efecto sobre las finanzas públicas, debido a que el país no había diversificado sus fuentes de ingreso a partir de nuevas formas de recaudación fiscal que fueran más eficientes y duraderas a largo plazo.

\section{Palabras clave}

Crecimiento económico, política tributaria, finanzas públicas.

\section{Abstract}

This article addresses the evolution of economic growth in Ecuador since 2008, as a result of the first tax reform by the government of former President Rafael Correa. Subsequently, in less than a decade, 22 tax reforms were launched, therefore it is important to review the definitive impact that these Tax Reforms have had on tax collection, as well as on the increase in public spending at the national level. It is observed that as a result of the implementation of this expansive fiscal policy, the Ecuadorian economy experienced economic growth, evidencing the dependence of spending on the country's oil revenues. As such, when these had a fall, they caused a serious effect on public finances, because the country had not diversified its sources of income, based on new forms of tax collection that were more efficient and durable in the long term.

\section{Keywords}

Economic growth, tax policy, public finances.

Códigos de clasificación JEL: E61, E62, E64. 


\section{Introducción}

Entre los años 2007 y 2014, la economía experimentó un crecimiento sostenido que fue sustentado por un nuevo auge petrolero $y$ la fuerte intervención estatal por medio de la política fiscal. Es conocido que a partir de 2007 se experimentaron profundos cambios en el sistema tributario; en concordancia, la administración tributaria hacía esfuerzos inmensurables, tanto por combatir las grandes brechas de evasión como por garantizar la redistribución de la riqueza, eficiencia administrativa y estimación en el impacto fiscal (Larraín \& Sachs, 2002; Alvear Haro et al., 2018).

En efecto, la primera reforma tributaria de noviembre de 2007 estuvo orientada por el concepto de que el Estado tiene la obligación de propender a una mejor distribución de la riqueza, por lo que se planteó un sistema tributario progresivo que debía procurar que los impuestos sirvan para disminuir las desigualdades y con ello lograr mayor justicia social (Asensio, 2015). En el mismo año, después de que el Gobierno anunció una "profunda" reforma para reducir las brechas entre ricos y pobres. En la norma aprobada por la Asamblea Nacional se incluyeron dos cambios para, según el régimen, "vencer el histórico cáncer social de la desigualdad". Los cambios fueron incrementar del impuesto a las herencias del $5 \%$ hasta el $35 \%$ y cambiar la tabla del impuesto a la renta para personas naturales, lo que elevó el tope del tributo del 25 al 35 \% (Heredia, 2016, septiembre 21).

Con este precepto se consideraba que el sistema tributario, a más de brindarle recursos públicos al Estado, debía permitir estimular la inversión, por lo que era necesario implementar un nuevo marco jurídico que posibilite el establecimiento de tributos justos y que graven al contribuyente sobre la base de su verdadera capacidad para contribuir (Ley Reformatoria para la Equidad Tributaria en el Ecuador, 2007).
El proyecto tributario ecuatoriano basado en criterios de progresividad no es nuevo, ya se había experimentado con el desarrollo de la Revolución juliana, en la cual se le arrebató el poder del sistema financiero ecuatoriano a la oligarquía terrateniente porque lo manejaba de manera abusiva. Ese cambio permitió introducir una nueva ley tributaria en el país, base para la creación del Banco Central del Ecuador (BCE) y la Superintendencia de Bancos. Estas instituciones comenzaron a elaborar y mantener estadísticas e informaciones más sistemáticas y confiables sobre el Ecuador (Paz y Miño Cepeda, 2015). Asimismo, se implementaron reformas en salud y derechos laborales. En suma, esos cambios representaron un avance para el Ecuador, principalmente porque se intentó cambiar los intereses del Estado; es decir, se buscó que este responda al interés nacional y no solo a intereses particulares (Goldschmidt, 1941; Paladines, 2007).

En la década de 1970, se iniciaron las labores de la Junta Nacional de Planificación y Coordinación Económica (Junapla), las cuales se enfocaban en el análisis del comercio exterior ecuatoriano, para lograr un modelo de crecimiento hacia afuera y para elaborar programas concretos con el fin de conseguir financiamiento externo (Paz y Miño Cepeda, 2015).

La reforma tributaria de 1964 encaró una modificación sustancial del régimen impositivo, estableció un impuesto único y personal, sobre la base de reunir todas las rentas obtenidas y entonces aplicar una tabla progresiva, que excluyó del pago a las rentas pequeñas, considerando el nivel mínimo vital de subsistencia y cargas familiares. (Paz y Miño Cepeda, 2015, p. 145)

Dicha reforma planteaba la necesidad de que los impuestos sean utilizados como un instrumento de redistribución de la renta (Steinmo, 2003). Es claro que después de la Primera Guerra Mundial, la mayor parte de los economistas expertos en política tributaria favorecían la progresividad impositiva y muy 
pocos apoyaban la reducción de impuestos a los ricos. Woker (2018) dice que Edwin Seligman fue el iniciador de las finanzas públicas progresistas al difundir el conocimiento sobre los impuestos por medio de una rica red global de académicos de finanzas públicas (Gaudemet, 1989). El conocimiento sobre la fiscalidad, la democracia y la redistribución comenzó a distribuirse a una escala sin precedentes, lo mismo que la importancia de las conexiones alemanas y francesas de Seligman y su influencia en la implementación del impuesto sobre la renta estadounidense. Además, Seligman planteó que el Estado tiene la capacidad de ejercer la coacción legal para cobrar impuestos (Echenique Romero, 2016).

Respecto a la equidad tributaria, Philip Taylor considera que existen muchas formas de definir lo que es equitativo, y muchas de esas ideas resultan ser vagas e inútiles cuando se intenta aplicarlas a problemas prácticos. "Es equitativo que las personas en la misma posición económica deban ser tratadas de la misma manera a los efectos de la fiscalidad" (Taylor, 1961, p. 45).

De acuerdo con Villacreses et al. (2015), las reformas tributarias implementadas entre 2007 y 2012 produjeron cambios significativos en la economía ecuatoriana, tal y como se plantea en el artículo 300 de la Constitución de la República del Ecuador (2008). Dicha reforma se basa en una nueva visión del sistema económica en general, donde el régimen tributario se fundamenta, por un lado, en los principios de generalidad, progresividad, eficiencia, irretroactividad, equidad, trasparencia y sapiencia recaudatoria, con un especial énfasis en la redistribución de la riqueza, y, por otro, en estimular siempre la producción de bienes y servicios, y las conductas ecológicas, sociales y económicas responsables; para mejorar la competitividad de las empresas del país integrando objetivos de la justicia social como la eficiencia económica.

\section{Comportamiento de las finanzas públicas ecuatorianas entre 2008 y 2020}

Ecuador es un país en el que los ingresos públicos se dividen en tres grandes grupos:

a. Petroleros

b. No petroleros

c. Superávit de la operación de las empresas públicas no financieras

Todo este ingreso se destinará para cubrir las obligaciones contraídas para la prestación de bienes y servicios públicos (Asensio, 2015).

El ingreso se clasifica en (Código Orgánico de Planificación y Finanzas Públicas, 2010):

- Ingresos permanentes: son aquellos ingresos que se mantienen durante un período de tiempo y que son predecibles. En este campo están los impuestos como el IVA, ICE, Impuesto a la Renta, a la salida de divisas, tasas aduaneras, entre otros.

- Ingresos no permanentes: son aquellos ingresos no predecibles en el tiempo. Aquí están los ingresos petroleros, la venta de activos, los desembolsos de créditos, entre otros.

Conocedores del impacto que puede tener el precio del petróleo sobre la economía ecuatoriana, para este análisis se explicarán los impactos fiscales con la clasificación de los ingresos petroleros y no petroleros.

\section{Ingresos petroleros}

La crisis ecuatoriana estuvo asociada a la baja internacional del precio del petróleo. Este problema no es nuevo en nuestra economía, debido a que en la década de 1980, de acuerdo 
con Fontaine (2002), los precios del petróleo también bajaron y el Ecuador tuvo que enfrentar serios desequilibrios económicos.

Es importante recalcar que, examinando las cifras del Banco Central y de la Administración de Información Energética de Estados Unidos (EIA), el precio promedio del barril de petróleo tipo West Texas Intermediate (WTI) - que sirve como referencia para el crudo ecuatoriano-, en 2013, era de 105.2 USD el barril. Para ese año, el Gobierno remitió a la Asamblea Nacional la proforma del presupuesto general del Estado (año 2013) con un monto de 32366.83 millones USD, y cerró el año fiscal con un déficit de 5059.7 millones USD, de acuerdo con las cifras publicadas por el Ministerio de Finanzas, al 31 de diciembre del 2013. En cuanto a los recursos devengados de la ejecución presupuestaria, en el siguiente año, el precio promedio del crudo ecuatoriano fue de 86.4 USD.

El precio del petróleo que al iniciar el 2015 se encontraba en 54.12 USD el barril, al mes de junio subió a 55.78 USD, en julio descendió en un $44.5 \%$ y en agosto se ubicó en 35.79 USD. El 7 de diciembre los precios del petróleo cerraron en su nivel más bajo en siete años, puesto que el el barril de light sweet crude (WTI), usado como valor referencial del producto ecuatoriano, llegó a 37.65 USD el barril en el New York Mercantile Exchange (NYMEX).

Posteriormente, el precio continuó bajando y, en 2016, se vendió hasta en 16 USD por varios días del mes de enero. En el primer trimestre del año el promedio fue de 24 USD, pero en abril subió a 31 USD. El impacto en las finanzas públicas fue muy grande, pues por cada dólar que cae el precio, hay un impacto de entre 70 millones y 80 millones USD en el presupuesto estatal. En 2017, las exportaciones petroleras generaron alrededor de 835 millones USD más que en el mismo lapso de 2016, según datos del BCE. Estos hechos ameritan estudiar de forma más detenida los impactos del inicial shock externo positivo sobre la economía del país, porque se infló el gasto público a la vez que se restó competitividad a otros sectores que se vieron afectados con la posterior caída del precio del crudo. Estos cambios en el precio internacional del petróleo se vieron reflejados en una merma de los ingresos petroleros del Gobierno ecuatoriano, como se puede ver en la tabla 1.

Tabla 1. Operaciones del sector público no financiero (1) (base devengado) (millones de dólares)

\begin{tabular}{|l|c|c|c|}
\hline \multicolumn{1}{|c|}{ Años } & Ingresos petroleros & Exportaciones petroleras & Venta de derivados \\
\hline 2008 & 4641.71 & 4641.71 & 0.00 \\
\hline 2009 & 2298.19 & 2298.19 & 0.00 \\
\hline 2010 & 4410.99 & 4410.99 & 0.00 \\
\hline 2011 & 5971.36 & 5971.36 & 0.00 \\
\hline 2012 & 10474.84 & 8150.22 & 2324.62 \\
\hline 2013 & 8876.24 & 6350.94 & 2525.30 \\
\hline 2014 & 7340.23 & 5311.60 & 2028.63 \\
\hline 2015 & 5283.12 & 3272.09 & 2011.03 \\
\hline 2016 & 4708.11 & 3391.79 & 1316.32 \\
\hline 2017 & 5647.05 & 4185.05 & 1462.00 \\
\hline 2018 & 8081.71 & 6210.45 & 1871.26 \\
\hline 2019 & 7660.56 & 5391.18 & 2269.38 \\
\hline 2020 & 4663.83 & 2745.27 & 1918.56 \\
\hline
\end{tabular}

Nota: Adaptado del BCE (www.bce.fin.ec) 
En 2020, se produjo la pandemia, lo que afectó la actividad económica mundial con la consecuente reducción de la demanda de petróleo. El precio del petróleo cayó notablemente; además, entre enero y agosto de 2020 la producción de crudo bajó un $13.3 \%$, al ubicarse en un promedio de 463373 barriles diarios, mientras que en el mismo periodo de 2019 ascendió a 534512 barriles por día. Es decir, hubo una reducción de 71139 barriles frente al periodo comprendido entre enero y agosto de 2019. En agosto, la producción cerró en 515467 barriles diarios o un $6.7 \%$ menos comparado con el mismo mes del año anterior. Esto equivale a una reducción interanual de 37164 barriles diarios (Torres \& Guerra, 2020).

Estos hechos afectaron de forma sustancial la renta gubernamental del Ecuador, por lo que los ingresos petroleros del Gobierno ecuatoriano bajaron en un $39.1 \%$. La baja de los precios del petróleo en los mercados afectó el presupuesto general del estado ecuatoriano, que ya tenía un déficit de más de 4000 millones USD. En 2020, se habían calculado ingresos por 35498.42 millones USD con un petróleo de 50 USD por barril.

Como consecuencia de la crisis, el expresidente Lenin Moreno adoptó un plan emergente. Entre las medidas se destacan (Valle Arancibia \& Aguirre, 2021):

- El 10 de abril de 2020 se creó la Cuenta Nacional de Asistencia Humanitaria, donde tanto el sector público como el privado debían contribuir para apoyar a la superación de la crisis. En particular, las empresas con más de 1 millón USD de servicios públicos debían contribuir con el $5 \%$ de ese servicio en tres pagos mensuales y los trabajadores que ganaran más de 500 USD mensuales debían entregar un aporte progresivo de acuerdo con su salario, durante los próximos nueve meses.

- El 14 de abril de 2020 se estableció una declaración para permitir que todos los aspectos relevantes para el funcionamiento de la economía fueran pactados entre los interesados, con el fin de preservar al máximo los empleos y fuentes de esos empleos. Por ejemplo, para evitar despidos, nuevos salarios y diferentes labores se puede acordar horas, así como prórrogas de plazos y períodos de gracia para saldar las deudas.

- Los funcionarios públicos debían contribuir con un porcentaje de su salario, y los de nivel superior debían aportar el $50 \%$ de su sueldo.

- Los pagos del impuesto a la renta de los meses de abril, mayo y junio de este año se aplazaron por 6 meses.

\section{Ingresos tributarios}

El impacto neto de las reformas tributarias en el periodo 2008-2014 alcanzó un monto de recaudación de ingresos tributarios de 65341.9 millones USD a favor de la administración tributaria. Los impuestos de los que se ha recibido mayor de recaudación son los indirectos IVA e ICE. A estos impuestos hay que restarles las reformas tributarias que han disminuido la recaudación por la eliminación de algunos rubros y por la creación de incentivos tributarios. Durante los años 20072012 se ejecutaron nueve reformas tributarias. Como resultado de ellas, la recaudación tributaria se vio afectada positivamente porque obtuvo un resultado neto positivo para el fisco de 1021.45 millones USD (tabla 2) (Villacreses, et al., 2015). 
Tabla 2. Operaciones del sector público no financiero. Ingresos tributarios (millones de dólares)

\begin{tabular}{|l|c|c|c|c|c|}
\hline \multicolumn{1}{|c|}{ Años } & Tributarios & A la renta & IVA & ICE & Arancelarios \\
\hline 2008 & 6426.4 & 2338.6 & 2824.9 & 473.6 & 789.3 \\
\hline 2009 & 6907.6 & 2517.5 & 3018.5 & 448.1 & 923.4 \\
\hline 2010 & 7921.9 & 2353.1 & 3886.1 & 530.2 & 1152.4 \\
\hline 2011 & 9004.4 & 3030.2 & 4200.4 & 617.9 & 1156.0 \\
\hline 2012 & 10589.3 & 3219.8 & 5421.3 & 684.5 & 1263.8 \\
\hline 2013 & 11868.1 & 3723.0 & 6077.8 & 743.6 & 1323.7 \\
\hline 2014 & 12624.2 & 4031.2 & 6412.9 & 803.3 & 1376.7 \\
\hline 2015 & 14228.6 & 4854.5 & 6501.9 & 845.7 & 2026.5 \\
\hline 2016 & 11903.7 & 3813.6 & 5660.7 & 798.3 & 1631.1 \\
\hline 2017 & 12659.7 & 4005.8 & 6229.6 & 949.4 & 1475.0 \\
\hline 2018 & 13721.6 & 4802.8 & 6381.1 & 978.3 & 1559.4 \\
\hline 2019 & 12892.7 & 4310.7 & 6270.0 & 898.5 & 1413.6 \\
\hline 2020 & 10917.0 & 4034.2 & 5200.8 & 737.5 & 944.5 \\
\hline
\end{tabular}

Nota: Adaptado del BCE (www.bce.fin.ec)

La recaudación tributaria en 2019 mostró un decrecimiento interanual desde 13721 millones USD a 12892 millones USD, lo que significa una disminución del $6.04 \%$. Esta reducción contempla los siguientes valores ocasionales: 1) la remisión tributaria por 1103 millones USD, y, 2) laudos arbitrales realizados en 2018 por 151.9 millones USD. Cuando se excluyen del análisis las recaudaciones ocasionales, se observa que la recaudación tributaria en 2019 incrementó en $2.9 \%$ frente al 2018.

Los impuestos indirectos tienen una participación de $55.6 \%$ mientras que los directos, el $44.39 \%$ dentro de los impuestos totales. La magnitud del multiplicador del gasto público del Ecuador es de 2.17 USD por cada dólar de gasto. Varios economistas consideran que el multiplicador está por debajo de lo que debería, posiblemente, entre otras razones, debido a la orientación del gasto público, ya sea corriente o de inversión.

\section{Política de gasto público y crecimiento económico}

A partir del año 2008, el Ecuador registró un crecimiento económico del $6.5 \%$ que, de acuerdo con la Organización de las Naciones Unidas (ONU) y la Comisión Económica para América Latina y el Caribe (CEPAL) (ONU \& CEPAL, 2010) obedeció especialmente al dinamismo del sector de la construcción (13.8\%), los servicios, la industria manufacturera y los servicios de la administración pública.

En cuanto al gasto público, se observa que continuó el proceso de aumento del gasto público obtenido en el año anterior, de manera que el gasto total del SPNF creció del $27.4 \%$ al $40.6 \%$ del PIB. Si bien la expansión del gasto obedeció al apreciable incremento de la formación bruta de capital fijo por parte del Estado, que subió desde un $6.9 \%$ del producto interno bruto (PIB) en 2007 hasta un $13.5 \%$ del PIB en 2008, también aumentaron marcadamente los gastos corrientes, incluidos el pago de salarios, las compras de 
bienes y servicios, las transferencias y otros gastos como el Bono de Desarrollo Humano (ONU \& CEPAL, 2010).

Es indudable que el Gobierno de Rafael Correa impulsó un modelo de crecimiento de tipo keynesiano, en el cual privilegió el papel estatal y recuperó el rol del Estado planificador. Durante esos años, el PIB de la economía tuvo una evolución creciente constante con variación promedio trimestral del $4.38 \%$. Estos años se caracterizaron por una alta volatilidad en el crecimiento económico, efecto de la fluctuación del precio del petróleo, lo que causó dos auges de crecimiento y dos caídas. El primer auge ocurrió en 2008, que se explica por el incremento del precio del petróleo, el cual obtuvo el nivel más alto hasta la fecha, de 98.72 USD de promedio trimestrales. Además, este auge fue dinamizado también, en mayor medida, por el sector manufacturero con un crecimiento promedio del $9.18 \%$, por el VAB del comercio con un $10.81 \%$, y, con menor fuerza, por los sectores de comunicaciones y suministro de energía y agua ( $20.85 \%$ y $30.03 \%$, respectivamente), además de la inversión extranjera directa (IED), que ya no solo se interesaba en la explotación petrolera.

De igual modo, si se examina el PIB por la oferta y utilización, se puede constatar que se dinamizó por un incremento del consumo de los hogares (5.39\%), formación bruta de capital fijo (FBKF) (16.06 \%), el consumo público (11.13\%) y por la variación de existencias (104.59\%).

La primera caída de la economía en términos reales se produjo en 2009, cuando el crecimiento de la economía, en términos reales, fue tan solo del $0.57 \%$. Este fenómeno fue ocasionado por el shock de la crisis financiera internacional que afectó principalmente a los precios del petróleo, que llegaron a los USD 63.81 por barril. Esta situación mostró los problemas estructurales de las finanzas públicas, debido a que los gastos crecían más rápido que los ingresos.

Del 2010 al 2014, a pesar de la recuperación relativa de los precios del petróleo, el crecimiento de los precios no fue el mismo. El precio del petróleo subió a 97 USD en 2011, con un crecimiento de la economía real del 7.87 \%. En 2012, la tasa de crecimiento bajó a $5.64 \%$ y en 2013 , a $4.95 \%$.

De acuerdo con la ONU y CEPAL (2013), en el Ecuador, la política fiscal mantuvo su trayectoria expansiva, aunque a tasas menores que las verificadas en años anteriores. Entre enero y julio de 2013, el gasto total del Gobierno central registró un aumento del $14.2 \%$ respecto al mismo período del año anterior. El gasto corriente aumentó un $16.5 \%$ en términos nominales, impulsado por alzas en el gasto de compras de bienes y servicios (26.3\%), el pago de intereses (44.9\%) y el pago de sueldos (8.5\%). El gasto de capital aumentó un $11.2 \%$ en ese mismo período, si bien el aumento de la inversión fija fue mayor (21.4\%). Aparte, los ingresos disminuyeron un $1.9 \%$, debido a la caída de los ingresos petroleros, que fue del $34.7 \%$, ya que los ingresos no petroleros crecieron un $16.1 \%$. Entre estos últimos, los ingresos tributarios se expandieron un $13.6 \%$ y los no tributarios, un $37.8 \%$. Como consecuencia, en el período analizado, el resultado del Gobierno central mostró un déficit, en contraste con el superávit registrado en igual período de 2012. Estos hechos hacen evidente que la política económica, en específico la fiscal, se convirtió en una herramienta pro cíclica, además de la falta de políticas para la estabilización macroeconómica (tablas 3 y 4). 
Tabla 3. Ecuador, gasto público (millones de dólares)

\begin{tabular}{|l|c|c|c|}
\hline \multicolumn{1}{|c|}{ Años } & Gastos totales & Gastos permanentes & Gastos no permanentes \\
\hline 2008 & 21762.2 & 14761.4 & 7000.8 \\
\hline 2009 & 20610.4 & 13930.2 & 6680.1 \\
\hline 2010 & 24122.6 & 16905.0 & 7217.6 \\
\hline 2011 & 31290.2 & 21942.6 & 9347.6 \\
\hline 2012 & 37965.1 & 25920.7 & 12044.4 \\
\hline 2013 & 45071.6 & 29100.0 & 15971.6 \\
\hline 2014 & 47081.7 & 30955.0 & 16126.7 \\
\hline 2015 & 42158.9 & 28901.3 & 13257.6 \\
\hline 2016 & 42192.0 & 27990.6 & 14201.4 \\
\hline 2017 & 41475.5 & 29707.2 & 11768.3 \\
\hline 2018 & 43304.5 & 32821.1 & 10483.4 \\
\hline 2019 & 42044.5 & 33733.5 & 8311.0 \\
\hline 2020 & 37791.7 & 30523.3 & 7268.4 \\
\hline
\end{tabular}

Nota: Adaptado del BCE (www.bce.fin.ec)

Tabla 4. Ecuador, oferta de bienes y servicios (millones de dólares)

\begin{tabular}{|l|c|c|c|}
\hline \multicolumn{1}{|c|}{ Años } & Producto interno bruto & Importaciones & Total oferta final \\
\hline 2008 & 61762.6 & 20933.4 & 82696.0 \\
\hline 2009 & 62519.7 & 16790.1 & 79309.8 \\
\hline 2010 & 69555.4 & 22541.7 & 92097.1 \\
\hline 2011 & 79276.7 & 26453.9 & 105730.5 \\
\hline 2012 & 87924.5 & 27772.1 & 115696.7 \\
\hline 2013 & 95129.7 & 29459.6 & 124589.3 \\
\hline 2014 & 101726.3 & 30168.3 & 131894.6 \\
\hline 2015 & 99290.4 & 23815.4 & 123105.8 \\
\hline 2016 & 99937.7 & 19004.7 & 118942.4 \\
\hline 2017 & 104295.9 & 22516.3 & 126812.2 \\
\hline 2018 & 107562.0 & 25554.0 & 133116.0 \\
\hline 2019 & 108108.0 & 24895.6 & 133003.6 \\
\hline 2020 & 98808.0 & 20506.1 & 119314.1 \\
\hline
\end{tabular}

Nota: Adaptado del BCE (www.bce.fin.ec)

Entre los últimos dos años de la presidencia de Rafael Correa (2007-2016) y la apertura del periodo de Lenin Moreno (2017-
2021) hubo otra caída del precio del petróleo, lo que ocasionó graves problemas a la economía, por la dependencia del precio del 
petróleo. Esta dependencia se reflejó en los ingresos fiscales, además de no aplicar el principio de ahorrar en periodos de abundancia y fortuna para tener en periodos de crisis, escasez, pobreza y penalidades, como recomienda Keynes. Esto, sin olvidar que es necesario tomar el consejo de Budnevich (2002) que pone como condición para una postura fiscal contra cíclica dos aspectos:
1) las cuentas fiscales deben ser solventes y sustentables, y, 2) una reingeniería de las instituciones correspondientes que incremente la oportunidad y flexibilidad de la política fiscal. En 2016, el país no contaba con ningún tipo de ahorro interno a lo que se sumó el terremoto del 16 de abril de ese año que afectó a las provincias costeras de Esmeraldas y Manabí (tabla 5).

Tabla 5. Ecuador, utilización de bienes y servicios (millones de dólares)

\begin{tabular}{|l|c|c|c|c|c|c|}
\hline Años & $\begin{array}{c}\text { Gobierno } \\
\text { general }\end{array}$ & $\begin{array}{c}\text { Consumo de } \\
\text { las familias }\end{array}$ & $\begin{array}{c}\text { Formación } \\
\text { bruta de capital } \\
\text { fijo }\end{array}$ & $\begin{array}{c}\text { Variación de } \\
\text { existencias }\end{array}$ & Exportaciones & $\begin{array}{c}\text { Total } \\
\text { utilización }\end{array}$ \\
\hline 2008 & 7306.8 & 37991.3 & 13818.5 & 2479.1 & 21100.4 & 82696.0 \\
\hline 2009 & 8581.3 & 38913.3 & 14257.7 & 1771.9 & 15785.7 & 79309.8 \\
\hline 2010 & 9181.1 & 44012.1 & 17127.9 & 2373.6 & 19402.4 & 92097.1 \\
\hline 2011 & 10091.2 & 48657.2 & 20470.8 & 1839.6 & 24671.8 & 105730.5 \\
\hline 2012 & 11726.8 & 53008.3 & 23707.8 & 731.5 & 26522.3 & 115696.7 \\
\hline 2013 & 13323.3 & 56941.9 & 26211.7 & 869.0 & 27243.5 & 124589.3 \\
\hline 2014 & 14543.0 & 60012.3 & 27684.2 & 1119.0 & 28536.1 & 131894.6 \\
\hline 2015 & 14327.1 & 60991.9 & 26390.5 & 289.0 & 21107.4 & 123105.8 \\
\hline 2016 & 14596.6 & 59889.7 & 25080.8 & -117.3 & 19492.6 & 118942.4 \\
\hline 2017 & 15197.2 & 62478.0 & 26496.3 & 913.0 & 21727.8 & 126812.2 \\
\hline 2018 & 15829.2 & 64202.3 & 27517.7 & 1252.7 & 24314.1 & 133116.0 \\
\hline 2019 & 15583.5 & 64496.5 & 26908.0 & 1098.5 & 24917.1 & 133003.6 \\
\hline 2020 & 14486.2 & 59722.0 & 23252.6 & -410.7 & 22264.0 & 119314.1 \\
\hline
\end{tabular}

Nota: Adaptado del BCE (www.bce.fin.ec)

En 2017, con la entrada de Lenin Moreno, los precios del petróleo tuvieron un aumento relativo de 44 USD promedio trimestrales en 2016 a 52 USD en 2017, aportando así al crecimiento de la economía.

La proforma del presupuesto general del Estado para el 2018 fue aprobada por la Asamblea. Las perspectivas del Gobierno reflejan un cambio en los ingresos y los gastos con respecto a lo planificado para el 2017. El Gobierno planteó una reducción en el presupuesto para enfrentar el déficit fiscal y el endeudamiento de los últimos 10 años.
En 2018, el Gobierno gastó 43304 millones USD, esto significa 1829 millones USD más de lo que se gastó en 2017 con un incremento del $4.4 \%$.

Sectores de la opinión pública han señalado el elevado gasto público que se ha mantenido durante los últimos 10 años. El alto precio del petróleo permitió subir cada vez más los gastos. Pero con la caída del precio del crudo, un ajuste se hizo necesario. Es así que el gasto de inversión, como lo llama el Gobierno, se reduce en $13 \%$ en el presupuesto para 2018, y se ubica en USD 4739 millones. Un recorte que contrasta 
con el aumento en otros rubros como el de personal o el de bienes y servicios para las instituciones públicas: se recorta la inversión y se aumenta el pago de sueldos a los servidores públicos. (Observatorio de Gasto Público, 2017)

Como lo hace notar Gómez Ponce (2019, noviembre 8), en 2019, el Gobierno ecuatoriano presentó su proforma presupuestaria 2019 con 5482 millones USD menos que hace dos años. Sin embargo, el gasto real fue de tan solo 1260 millones USD menos que el año 2018. Desde el punto de vista de Gómez Ponce (2020, diciembre 17), en los últimos cuatro años, el Gobierno ecuatoriano redujo el presupuesto destinado a educación, salud y trabajo. Conforme los registros de ejecución presupuestaria del Ministerio de Economía y Finanzas, 2020 fue el año en el que menos recursos se destinaron para las instituciones que conforman estos tres sectores. En contraste, se asignó un presupuesto mayor para bienestar social. El nivel de gasto público tuvo una reducción de 4253 millones USD en relación con el año 2019. Para lograr este objetivo fiscal se recortó 980 millones USD de la masa salarial, 400 millones USD de bienes y servicios y 1300 millones USD de gasto de capital.
"En igual sentido, el Gobierno ecuatoriano renegoció la deuda externa que tiene para ahorrarse 1300 millones de dólares en intereses. Para el año 2019 el FMl y otros organismos internacionales le prestaron 10300 millones de dólares" (Calle, 2020, mayo 20).

\section{Modelo de gasto público y crecimiento económico}

A fin de determinar la relación entre gasto público y crecimiento, se ha utilizado el modelo teórico básico de demanda interna, según el cual el nivel de producción (Y) debe coincidir con la demanda (D), en tres grandes apartados: consumo privado (C), inversión (I) y gasto público (G). Después se hizo la regresión lineal simple con los datos reales de gasto público, siendo la variable independiente $(X)$ y el PIB del Ecuador como variable dependiente, ambos en millones USD para los años 2008 y 2020.

En primer lugar, se estimó el modelo mediante regresión sobre toda la base de datos. Los resultados muestran una alta significación general con un R cuadrado ajustado de 0.88 , en lo que se refiere a la relación entre gasto y producción (tabla 6).

Tabla 6. Ecuador, estadísticos de regresión gasto público-producción

\begin{tabular}{|l|c|}
\hline \multicolumn{1}{|c|}{ Estadísticas de la regresión } & \\
\hline Regresión múltiple & 0.946135 \\
\hline R cuadrado ajustado & 0.895172 \\
\hline R cuadrado ajustado & 0.885643 \\
\hline Error estándar & 5653.818 \\
\hline Observaciones & 13 \\
\hline
\end{tabular}

Con el fin de desarrollar las estimaciones apropiadas, se hizo el test de Hipótesis F. Se detectó que la hipótesis de nulidad se rechaza, por lo que, en forma preliminar, se puede afirmar que se acepta que existe una relación entre crecimiento económico, identificado por el PIB, y gasto público (tabla 7). 
Tabla 7. Ecuador, Resultados del test de Hipótesis gasto público-producción

\begin{tabular}{|l|c|l|l|l|c|}
\hline & df & \multicolumn{1}{|c|}{ SS } & \multicolumn{1}{|c|}{ MS } & \multicolumn{1}{c|}{ F } & Test de Hipótesis \\
\hline Regresión & 1 & $3 \mathrm{E}+09$ & $3 \mathrm{E}+09$ & 93.93412 & $0 \%$ \\
\hline Residual & 11 & $3.52 \mathrm{E}+08$ & 31965654 & & \\
\hline Total & 12 & $3.35 \mathrm{E}+09$ & & & \\
\hline
\end{tabular}

Para finalizar, se revisó la consistencia teórica del modelo y se constató que el PIB está fuertemente correlacionado con el de gasto público, con un coeficiente de elasti- cidad al gasto del ingreso de 1.72, propio de una economía altamente dependiente del Estado (tabla 8).

Tabla 8. Ecuador, coeficiente de ecuación de regresión lineal gasto público-producción

\begin{tabular}{|l|l|}
\hline & \multicolumn{1}{c|}{ Coeficientes } \\
\hline Intercepción & 27050.22831 \\
\hline Gasto & 1.728442503 \\
\hline
\end{tabular}

\section{Discusión y conclusiones}

El Ecuador es un país que se caracteriza por la fuerte presencia del Estado en la economía, es claro que un incremento de la demanda debe provenir de cualquiera de los componentes del $P I B=C+G+F B K F+X$. En épocas de recesión, los agentes económicos reducen su nivel de consumo, la falta de consumo reduce los ingresos de las empresas y esta falta de ingreso obliga a los empresarios a reducir personal, por este motivo, es necesaria la intervención del Estado en la economía. De acuerdo con el concepto del multiplicador del gasto, mientras mayor sea la propensión marginal al consumo, más efectiva será la intervención del Estado a través del incremento del gasto público. Al respecto, Jahan et al. (2014, p. 54) afirman que "según la teoría keynesiana, la intervención estatal es necesaria para moderar los auges y caídas de la actividad económica, es decir, el ciclo económico".

El mecanismo que planteó Keynes para reactivar la economía fue la presencia fuerte y vigorosa del Estado por medio del gasto público. Estos mecanismos de mercado no son del todo eficientes como se había planteado en la teoría clásica, por lo que es necesaria la intervención estatal. Al generar gasto público, los agentes económicos dispondrán de renta, por consecuencia, la demanda potencial se transformará en demanda efectiva, lo que propiciará el crecimiento del empleo, del ahorro y de la inversión, pues, según Keynes, en el mercado no existen mecanismos que aseguren tal ajuste.

El gobierno de Rafael Correa, durante la década que ejerció el poder, aplicó un modelo de incremento del gasto público, acompañado de una política tributaria de tipo redistributiva. El modelo tuvo un éxito en los primeros 6 años de aplicación, pero, con la crisis de los precios del petróleo, el Gobierno tuvo un doble impacto fiscal. A esto se suma que al tener una dolarización como sistema monetario, se produjo un segundo impacto en las cuentas externas con la consecuente caída de la liquidez interna en el país.

El Gobierno no ajustó su nivel de gasto público por considerarlo recesivo y prefirió incrementar la deuda pública, incluyendo no 
solo los préstamos tomados por el Gobierno Central, sino también los que contraen organismos regionales o municipales, institutos autónomos y empresas del Estado, ya que estos son garantizados por el Gobierno Nacional.

Es necesario contar con un Estado que tome en cuenta los principios de eficiencia, probidad y transparencia, con envolvimiento de un nuevo tipo de acción controladora. En el caso del Ecuador, una buena parte del gasto público se canaliza al gasto corriente y ese tipo de erogaciones tiene poco impacto sobre la producción a través del tiempo. Otras posibles causas de su bajo nivel son la falta de eficiencia con que se ejerce el gasto, y la corrupción. Ambas provocan incremento en el costo de las obras y, por lo tanto, el impacto sobre la demanda agregada y la producción de cada dólar gastado es menor de lo que debería de ser.

\section{Referencias}

Alvear Haro, P. F., Elizalde Marín, L. K., \& Salazar Tenelada, M. V. (2018). Evolución del sistema tributario ecuatoriano y su influencia en el presupuesto general del Estado. Observatorio de la Economía Latinoamericana, (240), 1-13. https://bit.ly/3c7WqiE

Asensio, M. Á. (2015). Finanzas públicas: Notas de orientación. Osmar D. Buyatti.

Budnevich, C. (2002). Countercyclical fiscal policy: A review of the literature, empirical evidence and some policy proposals. Discussion Paper. World Institute for Development Economics Research. https://bit. ly/3qstaLy

Calle, M. (2020, mayo 20). Este es el plan de Ecuador para bajar el gasto público durante la pandemia. France24.com. https:// bit.ly/2ZIHzc4

Código Orgánico de Planificación y Finanzas Públicas. (2010). Registro Oficial 306, Segundo suplemento, 22 de octubre.

Constitución de la República del Ecuador (2008). Registro Oficial 449, 20 de octubre.
Echenique Romero, X. (2016). La construcción de una política tributaria en México. Economía Informa, 398, 75-88. https://doi. org/10.1016/j.ecin.2016.04.006

Fontaine, G. (2002). Sobre bonanzas y dependencias: Petróleo y enfermedad holandesa en el Ecuador. Revista Íconos, (13), 102-110. https://bit.ly/2YKXRRm

Gaudemet, J. P. (1989). Finanzas públicas y desarrollo: Coloquio Franco-Latinoamericano. Grupo Editor Latinoamericano; Colección Estudios Políticos y Sociales.

Goldschmidt, A. (1941). El impuesto progresivo: Historia, teoría y práctica. Investigación Económica, 1(1), 85-114. https://bit. ly/3CdpEHH

Gómez Ponce, L. (2019, noviembre 8). Novedades y sorpresas en la proforma presupuestaria 2019. Observatorio del Gasto Público. https://bit.ly/3pOeF50

Gómez Ponce, L. (2020, diciembre 17). 2020: Un año de reducciones en el presupuesto para los sectores sociales. Observatorio del Gasto Público. https://bit.ly/3w0qLcn

Heredia, V. (2016, septiembre 21). 22 reformas tributarias en casi una década en Ecuador. El Comercio. https://bit.ly/3BweLQM

Jahan, S., Ahmed, S. M., \& Papageorgiou, C. (2014). ¿Qué es la economía keynesiana? Finanzas \& Desarrollo, (sept.) 53-54.

Larraín, B. F., \& Sachs, J. D. (2002). Macroeconomía en la economía global. Pearson Educación.

Ley Reformatoria para la Equidad Tributaria en el Ecuador (2007). Registro Oficial 242, Tercer suplemento, 29 de diciembre.

Observatorio de Gasto Público. (2017, diciembre 11). El presupuesto 2018: ¿Dónde está la austeridad?. https://bit.ly/3GBXxWO

Organización de las Naciones Unidas \& Comisión Económica para América Latina y el Caribe. (2010). Estudio económico de América Latina y el Caribe 2008-2009: Políticas para la generación de empleo de calidad (LC/G.2410-P). https://bit.ly/3kwhNii

Organización de las Naciones Unidas \& Comisión Económica para América Latina y el Caribe. (2013). Balance preliminar de las economías de América Latina y el Caribe 2013 (LC/G.2581-P). https://bit.ly/3C5QGkk 
Paladines, E. (2007). Cumplimiento y nivel de progresividad del impuesto a la renta de las personas naturales en Ecuador 2001-2005. Cuestiones Económicas, 23(1),125-155.

Paz y Miño Cepeda, J. (2015). Historia de los impuestos en el Ecuador: Visión sobre el régimen impositivo en la historia económica nacional. Servicio de Rentas Internas.

Steinmo, S. (2003). The evolution of policy ideas: Tax policy in the 20th Century. The British Journal of Politics and International Relations, 5(3), 206-236. https:// doiorg/10.1111/1467-856X.00104

Taylor, P. (1961). Economics of public finance (3. ${ }^{a}$ Ed.). Macmillan.
Torres, W., \& Guerra, S. (2020, septiembre 4). Producción petrolera cierra con fuerte caída en los primeros ocho meses de 2020. Primicias. https://bit.ly/31k5L51

Valle Arancibia, A., \& Aguirre, I. (2021). Panorama económico del Ecuador. Apuntes de Economía, (64), 1-27.

Villacreses, N., Oña, A., \& Rea, S. (2015). Análisis de las reformas tributarias 2007-2012. Centro de Estudios Fiscales SRI, (22), 1-11.

Woker, M. (2018). Edwin Seligman, initiator of global progressive public finance. Journal of Global History, 13(3), 352-373. https://doi. org/10.1017/S1740022818000190 